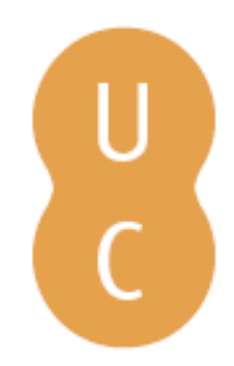

\title{
pommalina
}

\section{Píndaro e Horácio face a face}

Autor(es): Viana, Maria Mafalda de Oliveira

Publicado por: Associação Portuguesa de Estudos Clássicos; Imprensa da Universidade de Coimbra

URL

persistente: URI:http://hdl.handle.net/10316.2/31766

DOI: $\quad$ DOI:http://dx.doi.org/10.14195/978-989-721-069-3_16

Accessed : $\quad$ 26-Apr-2023 13:48:45

A navegação consulta e descarregamento dos títulos inseridos nas Bibliotecas Digitais UC Digitalis, UC Pombalina e UC Impactum, pressupõem a aceitação plena e sem reservas dos Termos e Condições de Uso destas Bibliotecas Digitais, disponíveis em https://digitalis.uc.pt/pt-pt/termos.

Conforme exposto nos referidos Termos e Condições de Uso, o descarregamento de títulos de acesso restrito requer uma licença válida de autorização devendo o utilizador aceder ao(s) documento(s) a partir de um endereço de IP da instituição detentora da supramencionada licença.

Ao utilizador é apenas permitido o descarregamento para uso pessoal, pelo que o emprego do(s) título(s) descarregado(s) para outro fim, designadamente comercial, carece de autorização do respetivo autor ou editor da obra.

Na medida em que todas as obras da UC Digitalis se encontram protegidas pelo Código do Direito de Autor e Direitos Conexos e demais legislação aplicável, toda a cópia, parcial ou total, deste documento, nos casos em que é legalmente admitida, deverá conter ou fazer-se acompanhar por este aviso.

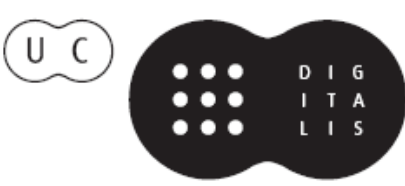




\section{Espaços e Paisagens}

\section{Antiguidade Clássica e Heranças Contemporâneas}

Vol. I Línguas e Literaturas. Grécia e Roma

Francisco de Oliveira, Cláudia Teixeira, Paula Barata Dias (coords.)

IMPRENSA DA UNIVERSIDADE DE COIMBRA 


\title{
PÍNDARO E HORÁCIO FACE A FACE
}

\author{
Maria Mafalda de Oliveira Viana \\ Universidade de Lisboa \\ viana.mafalda@sapo.pt
}

\section{Résumé}

L'espace poétique de la recusatio au carmen 4, 2 d'Horace accueille de façon particulière l'œuvre de Pindare. Le poète latin, en même temps qu'il dit de Pindare qu'il est un poète qu'on ne peut pas émuler, poursuit la recherche du sens des vers de celui-ci. Nous croyons que ce discours ambigu est celui d'une sincère modestie qui essaye de transmettre et de traduire de façons diverses le texte de Pindare.

Mots clés: aemulatio, Horace, Pindare, poésie lyrique, traduction.

Palavra-chave: aemulatio, Horácio, Píndaro, poesia lírica, tradução.

Quando Horácio regressa à lírica, escrevendo o livro 4 das odes, podemos hoje dizê-lo, estava assegurada a perenidade de um monumentum, cuja durabilidade tem origem no compromisso de quem, ao exprimir o seu desejo em crescam laude recens, está consciente de que a grandeza de um poeta se mede pela capacidade de aparecer sempre novo ao longo dos séculos. Pindarum quisquis studet aemulari ostenta o desprendimento (mesmo se laboriosamente fingido) de quem fortalecera a língua latina com os antigos ritmos arcaicos da lírica de Alceu e Safo. Regressa mais grave, em plena maturidade e muito embora o exercício de recusatio da ode 4, 2, ou a expressão de uma pelo menos aparente humildade de quem recua perante a grandiosidade do modelo grego pudessem induzir no leitor a ideia de que o poeta sente a dificuldade própria da inexperiência ou incapacidade pura e simples como poeta, a largueza e o à vontade com que maneja a língua latina para exprimir de forma multifacetada o que é a poesia pindárica obrigam-nos a um recuo. A sua humildade é a da abelha laboriosa. Mestre no labor do pormenor, só ela conhece de que é feita a abundância e multiplicidade de reflexos da poesia de Píndaro e sabe que dizerse desse poeta que ele é inimitável é coisa justa e própria de quem na sua arte é um princeps.

O contexto histórico do mundo grego arcaico, que implica o significado da obra poética de Píndaro, não tem paralelo em épocas posteriores e dificilmente alguma vez se repetiria. Mesmo nas relações entre patrono e poeta não há uma equivalência estreita entre um e outro espaço: a lírica de Píndaro estava socialmente implantada como parte de uma tradição na qual os papéis do poeta e do patrono eram bem conhecidos. Por outro lado, o poeta, ainda que nem 
sempre o faça de forma muito clara, mostra frequentemente alguma relutância em imitar o lírico grego, pois prefere a aemulatio; com efeito, Horácio, então autor de três livros de odes, embora em muitos casos mostre conhecer bem a lírica de Píndaro, prefere apresentar-se como o poeta que adaptou aos ritmos da língua latina os versos eólicos, experimentando nela possibilidades de alargamento a novos ritmos onde sintetiza uma cadência de vida humana pautada pela consciência justa da necessidade de um fim (2, 14, 21-24):

\author{
linquenda tellus et domus et placens \\ uxor, neque harum, quas colis arborum \\ te prater inuisas cupressos \\ ulla breuem dominum sequetur. \\ a terra se deve deixar, a casa e a complacente \\ esposa; e dessas árvores que cuidas, \\ fora o mal visto cipreste, a ti, \\ breve senhor, nem uma te acompanhará
}

Apesar de ser comum a justeza dos versos que se abstêm de dizer mais do que o estritamente necessário, outro e diverso é o modo lírico do carmen 4, 2, onde o nome de Píndaro é suficiente para mover a disponibilidade do leitor, que deverá abrir-se ao espaço psicológico do lirismo que modela a vida de acordo com a claridade dos grandes espaços abertos, lugar de triunfo e celebração festiva - tudo o que decerto justificaria o termo magnificentia usado por Quintiliano (I.O. 10,1,6) para classificar a obra de Píndaro. É certo que não voltaria a repetir-se o contexto específico da lírica arcaica de Simónides, Baquílides e de Píndaro, mas o regresso de Augusto, ausente em campanha na Gália, e todo o aparato dos festejos devidos à sua celebração pareciam conter os ingredientes necessários a uma composição deste estilo. Além disso, poucos anos antes, Horácio compusera o Carmen Saeculare a pedido do imperador que, após a morte de Virgílio, procurava restaurar os Jogos Seculares em 17 a. C., inaugurando desta forma uma nova idade para Roma. E embora o convívio com um Horácio desprendido nos habitue a encontrar nos seus versos a cadência de vida, a mesma capacidade da justa e sintética medida com que a canta na sua aurea mediocritas servia agora no Carmen Saeculare para glorificar a Roma aeterna ${ }^{1}$. Assim terá parecido a Julo ao sugerir-lhe a composição de uma ode para integrar os festejos do regresso de Augusto. A Julo é por isso dirigida a ode 4, 2, mas ao pedido deste responde o poeta em forma de recusatio. Recusa de compor uma ode ao modo de Píndaro: mas em que sentido? Porque o poeta - que se orgulha de ter conduzido aos ritmos itálicos os versos eólicos

${ }^{1}$ Tanto o carme horaciano como os epinícios de Píndaro são cantos corais pensados para uma apresentação pública perante uma audiência; para uma equivalência de elementos, v. M. Putnam (2000), Horace's Carmen Saeculare. Ritual, Magic and the Poet's Art. New-Haven and London, 104-112. 
- se acha incapaz, ou, como sugere E. Fraenkel ${ }^{2}$, porque o poeta consideraria desapropriada uma ode pindárica para este contexto? De acordo com esta interpretação são lidos os versos 45-48, onde há reconhecidamente uma quebra no tom dos versos anteriores. Adequado à ocasião seria o singelo 'o sol / pulcher, o laudandé.

Porém, não nos parece que devamos levar sempre a sério as afirmações do poeta,quando ele recusar determinada atitude.Píndaro, ao recusar explicitamente o caminho longo, optando por um caminho breve, fá-lo numa ode com 299 versos $^{3}$, pelo que deverá o leitor procurar outro sentido que não seja o de uma recusa pura e simples. A leitura do pormenor leva-nos a pensar que a recusatio tem muito de pose literária, situação de que outras odes dão testemunho e tem enquadramento adequado, porquanto o poeta se insere num movimento de poesia que vê em poetas alexandrinos sofisticados como Teócrito e Calímaco o seu modelo; no entanto, servindo-se de um topos que bem conhece, o poeta não deixa de ser sincero na afirmação inicial. Por outro lado, como atitude literária, está em causa também uma opção do poeta que põe em confronto a figura forte e pesada dos touros e das vacas e a de um ligeiro uitulus (53-56). A influência da escola alexandrina que recusa a poesia de grande fôlego é um dos aspectos a ter em conta na recusatio; no contexto específico da ode, onde se trata de aferir a possibilidade de Píndaro ser igualado, lembramos que a afirmação do poeta relativamente à narrativa de grande fôlego tivera já o seu início, entre outros poetas, com Píndaro: sem rejeitar categoricamente a tradição da narrativa épica, mas assumindo dela muitos elementos, ele indica um caminho novo para a narrativa, referindo-se-lhe mesmo, em alguns casos, de forma explícita ${ }^{4} \mathrm{Na}$ imagem de Horácio, a ideia é a de um uitulus, um novilho que, muito embora aprenda a tornar-se independente da sua mãe, dela descende. Possibilidade que não anula inteiramente a anterior é a de pensarmos que se trata não de um confronto entre a narrativa de grande fôlego e a lírica, mas entre dois modos líricos: a lírica de Píndaro, majestosa, de que encontramos reflexo no Carmen Saeculare, e a lírica de cariz mais individualista ${ }^{5}$.

O problema com a forma de recusatio é que o poeta parece ora dizer, ora não dizer: na primeira estrofe, as palavras do sujeito parecem ser completamente dissuasoras da possibilidade de chegar perto de Píndaro; no entanto, no prosseguimento da leitura das estrofes subsequentes, o leitor depara com uma alusão minuciosa a Píndaro que, de forma dissimulada, se entretece por entre as palavras e a sintaxe que numa primeira leitura explanam as várias vertentes da sua obra. Ao antigo exercício de síntese feito por Píndaro, Horácio sobrepõe

${ }^{2}$ E. Fraenkel (1957), Horace, Oxford. 432-440.

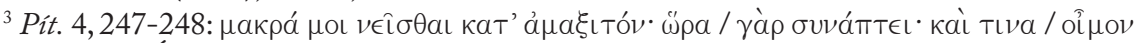

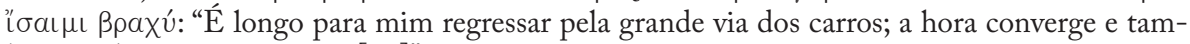
bém conheço uma via curta $[\ldots]$ ”

${ }^{4}$ A Pítica 4 é um bom exemplo do que dizemos. Cf. M.M.Viana, Natureza e Arte. Leituras de Pindaro (2005), Dissertação de Doutoramento. Univ. do Algarve, 147-207.

${ }^{5}$ Lidos os versos à luz da estrofe 9, esta possibilidade parece-nos plausível. Cf. E. Romano (1991), Le Odi, il carme secolari, gli epodi, t. 2, commento. Roma, 857. 
uma nova síntese. Com Píndaro se testemunha de forma privilegiada no género lírico um movimento paulatino de construção na sombra de um género panorâmico anterior, cuja narrativa dos já então antigos heróis os seus novos versos desafiam e reconfiguram em novo espaço, onde a longa narrativa não tinha já lugar. Como porventura não sem algum sentimento de rivalidade o maior lírico grego respondia à observação de Simónides segundo a qual o novo vinho não era ainda convincente ${ }^{6}$, Horácio, em diferente contexto, mas com não menor sentimento de aemulatio desafia agora, também ele, tener uitulus, um poeta seu contemporâneo, cuja poesia parecia ter, pelo contrário, o estatuto de decem tauri. Mas a analogia de Horácio não termina aqui; a expressão de rivalidade está enquadrada no topos da recusatio, que, neste contexto, serve ao poeta para exprimir um outro tipo de aemulatio: a do poeta latino que como nenhum outro conhece as limitações de se igualar um poeta como Píndaro. É o que fica claro logo na primeira estrofe. A imagem da aparatosa queda de Ícaro, que pretendera subir mais alto do que o devido, ajustada à tentativa de igualar o lírico grego parece-nos, neste contexto da literatura latina, atitude de quem considera a língua grega de Píndaro com a aura atemporal de uma Ur-Sprache, numa aurora irrepetível, no sentido em que esta seria intraduzível. Com tal atitude, o poeta parece dar razão àqueles a quem Cícero criticava por desprezarem antigos poetas como Énio ou Pacúvio, preferindo ler as peças de Eurípides (De fin. 1, 2, 4-5). A esta luz, parece justa a observação de Cupaiuolo que vê a recusatio como acto de sincera modéstia de quem está consciente de que a sua poesia não pode alcançar a altura da Musa pindárica ${ }^{7}$. Além da especificidade de Píndaro, poeta que não foi dos mais imitados ao longo dos séculos, o temperamento de Horácio e sobretudo a consciência de quem sabe como ninguém o que significa para a língua latina introduzir-lhe ritmos que lhe são alheios, permitem-nos enquadrar a justeza daquela presunção. No entanto, de forma até usual em Píndaro, após a negação, o poeta ocupa metade da ode com referência explícita à obra deste. Como interpretar o que parece ser inconciliável? O poeta grego é immensus; o carácter multifacetado dos seus versos não conhece medida, sendo nesse sentido inigualável. Mas será intraduzivel? Que mais dizem os versos para além de uma leitura imediata que ali encontra a enumeração de várias vertentes da obra de Píndaro? Num artigo sobre a recusatio horaciana, Peter Smith refere-se a várias facetas de uma "ambivalência" de Horácio ${ }^{8}$. Considerando a justeza da observação, pensemos que o poeta ilude o leitor convencendo-o de que considera o poeta grego inigualável, mas na medida em que procura a reaç̧ão do doctus que conhece

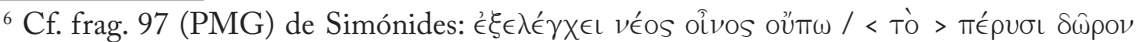

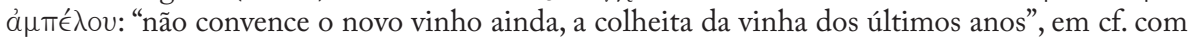
Ol. 9, 48-49: alı as flores dos hinos mais novos".

${ }^{7}$ F. Cupaiuolo (1967), Lettura di Orazio Lirico. Napoli 45-46. A. la Penna (1968), Orazio e la Morale Mondana Europea. Firenze 155-162, observa que ninguém como Horácio se dava conta da audácia do empreendimento

${ }^{8}$ P. Smith (1968), "Poetic Tensions in the Horatian Recusatio", AJPh 89.1 56-65. 
o processo literário em causa. Deste modo iludido o leitor, o poeta prossegue com a explanação da obra do lírico grego, com o que parece exprimir um sentimento enquadrável como antecedente da sensibilidade para questões de tradução conforme expressas em S. Jerónimo (Ad Pamachium, entre outras; Prol. in libro Job, 18), mas já visíveis em Cícero (De fin. 3,5). Neste caso, seria a tradução possível da obra de um poeta que, por ser immensus no fluir dos versos de múltiplos subentendidos, é por excelência o mais intraduzivel dos poetas. É o que parece estar subjacente à estrofe 2. Perante a abundante torrente fértil de versos para os quais é difícil encontrar uma mensura que os domestique, Horácio não procura igualá-lo, o que seria imprudente. Mas também não se limita a presumir que é intraduzível a especificidade da língua de Píndaro. Ao mostrar-se consciente de que irrepetíveis são quer a língua específica de Píndaro, quer a língua que o antecede e bem assim o espaço comunitário que a alimenta - apercebendo-se portanto de que a sua apreensão profunda e sentida da obra de Píndaro é impossível de parafrasear - , aceita a historicidade do homem. Renuncia a uma tradução perfeita, ao mostrar-se disponível nos versos subsequentes para o exercício de abertura da sua língua àquilo a que P. Ricoeur se refere como "hospitalidade linguística" ": abertura da língua à compreensão do outro e do diferente e estrangeiro que são para a língua de Horácio o espaço e o tempo de Píndaro.

Procurando, pois, dizer em latim o que é essa língua única e intraduzível de Píndaro, Horácio move-se de modo ambivalente. O enunciado dos versos 13 e 14 lembra a formulação dos primeiros versos da Olímpica 2 de Píndaro ${ }^{10}$, parafraseada na ode 1,12,1-4. Logo neste primeiro nível nos apercebemos de que o poeta se disponibiliza para esse "manifold act" que, segundo Steiner, preside a toda a leitura e compreensão profunda de um texto ${ }^{11}$. À antiga pergunta de Píndaro, cuja formulação espera uma resposta em acusativo, Horácio responde com uma enumeração designativa do objecto do canto de Píndaro entre as estrofes 3-6; aqui vão sendo aludidos os vários géneros: o ditirambo, o hino, o epinício, o treno. No entanto, tal como no texto de Píndaro a resposta não fica completa nos termos estritos de um acusativo, no texto horaciano, por entre um discurso enumerativo cuja sintaxe é do tipo sujeito, verbo, complemento directo que parece resolver a questão do objectum do canto, um discurso também ele immensus é construído para funcionar de modo ambivalente: mais do que indicar o suposto objecto do canto pindárico, ele tece-se de forma a aludir, minuciosa mas subtilmente, ao texto de Píndaro. Tal é o modesto trabalho da abelha. A título de exemplo, na estrofe 5, o que parece ser referência neutra ao canto do epinício - alusão ao cavaleiro e ao atleta do pugilato, que beneficiam de um canto de valor superior a cem estátuas - na

${ }^{9}$ P. Ricoeur (2004), Sur la traduction : Sobre a Tradução (2005), trad. M. Jorge Figueiredo. Lisboa, Cotovia, 23-53.

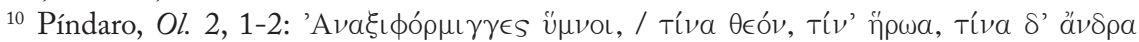

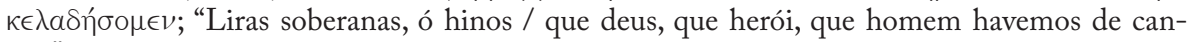
tar?".

${ }^{11}$ G. Steiner (1992), After Babel. Aspects of language and translation. Oxford, 1-50. 
verdade significa mais do que o permitido pela estrita sintaxe: do discurso emerge a veemente recusa de Píndaro que nos primeiros versos da Nemeia 5 afirma o carácter móvel da sua arte, face à imobilidade da obra do escultor. Quando esperávamos que todas as possibilidades de significado implicadas na estrofe 2 associadas à imagem da água estivessem esgotadas, a referência à ode pindárica na estrofe 5 retoma a simbologia anterior, agora associada ao movimento esquivo das águas - simbologia essencial nas odes de Píndaro. Figuras marinhas como Tétis e outras Nereides, cuja simbologia está associada à mobilidade das águas, são elementos importantes na linguagem de Píndaro: na Nemeia 5, as qualidades de Hipólita, a heroína do discurso móvel e enganador, são as mesmas do discurso do poeta e da marinha Nereide, a que dificilmente se deixa apanhar, pois conhece a arte de tomar múltiplas formas. O mesmo valor se encontra na simples alusão à Quimera, na estrofe 4.

Além destes aspectos, também na construção dos espaços na composição entra toda uma tradição poética cujo expoente é visível em Píndaro. Vários autores, com diferença de pormenor, consideram que a ode 4,2 apresenta duas partes perfeitamente equilibradas em correspondência recíproca, intercaladas por duas estrofes intermédias de confronto entre Horácio e Píndaro - a abelha e o cisne -, confronto com reflexo ainda na comparação entre a poesia simbolizada pelo touro e pelo novilho. Assim, poderíamos entender a primeira parte da ode como espaço da composição equivalente ao da narrativa mítica nos epinícios. Não será afinal o estatuto de poeta inigualável de Píndaro suficiente para que possamos enquadrá-lo na ode com o estatuto de herói? Tal como sobre o novo herói da narrativa mítica se diz que laurea donandus Apollinari (9), a César, em novo espaço, se diga o sol/ pulcher, o laudande (46-47). Deste modo estariam presentes já no poeta romano os primeiros indícios do tipo de leitura sistematizada no século XIX, por Boeckh e Dissen, que interpretam o mito em Píndaro com função alegórica de relação com o atleta / tirano elogiado.

Por fim, a translatio horaciana deixa ainda bem evidenciada a figura da primeira pessoa em Ego apis Matinae, a meio do verso 27, de forma a marcar uma paragem no ritmo sintáctico anterior ${ }^{12}$. Como em Píndaro, a referência ganha força significativa na medida em que ressoa no restante corpo da composição; na última estrofe, cuja sofisticada elaboração significa para além do efeito decorativo, é, pois, reenquadrada a afirmação de modéstia. A descrição do uitulus, cuja simbologia o sujeito tomara para si, reúne alguns termos da antiga descrição de um cavalo no canto 23 da Ilíada, que tem também na fronte uma marca branca arredondada como a lua. Mas que traz implícito a alusão? A apropriação dos versos não é passiva. Além da sua figura, este cavalo tinha a particularidade de seguir à frente, parecendo libertar-se de Diomedes. Com efeito, a configuração do texto homérico (Il. 23, 448-472) parece sugerir que, primeiro, um só cavalo vinha à frente, referindo-se só posteriormente, e após alusão ao dano presumivelmente sofrido na planície pelas éguas, aos cavalos de Diomedes, vencedor. A alusão a este episódio em Mosco $(2,80-87)$ para

\footnotetext{
${ }^{12}$ Cf. Píndaro, Nemeia 1, 33.
} 
descrever o touro em que Zeus se transformara para seduzir Europa confirma o mesmo movimento de libertação, porquanto o touro se distingue da manada por estar fora do estábulo e não estar preso ao trabalho da charrua. A imagem de Horácio refere-se assim simultaneamente a Píndaro, que, como o cavalo, da lei da narrativa épica se liberta, e a Horácio, tener uitulus, que recusa o pedido de Julo, justamente o autor de uma Diomedeia.

Não será esta uma atitude equivalente à de um tradutor que disponibiliza a sua língua e de forma multímoda procura compreender o texto que lhe é estranho? A expressão de sincera modéstia que Cupaiuolo encontra na recusatio horaciana não nos parece incompatível com o lugar de Horácio entre os poetas latinos. Que pelos séculos os seus versos conheçam merecida expressão renovada na cultura ocidental não constitui obstáculo a que na sua ode 4, 2 Horácio abra um espaço largo, onde, novos, os versos do maior lírico grego crescem e se expandem. 